\title{
Os imunobiológicos na proteção da saúde conhecendo sua história
}

\author{
Edson Alves de Moura Filho
}

\section{SciELO Books / SciELO Livros / SciELO Libros}

MOURA FILHO, E.A. Os imunobiológicos na proteção da saúde: conhecendo sua história. In: SILVA, M.N., FLAUZINO, R.F., GONDIM, G.M.M., eds. Rede de frio: fundamentos para a compreensão do trabalho [online]. Rio de Janeiro: Editora FIOCRUZ, 2017, pp. 215-238. ISBN: 978-65-5708-091-7. https://doi.org/10.7476/9786557080917.0010.

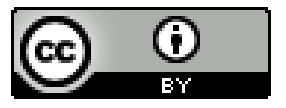

All the contents of this work, except where otherwise noted, is licensed under a Creative Commons Attribution 4.0 International license.

Todo o conteúdo deste trabalho, exceto quando houver ressalva, é publicado sob a licença Creative Commons Atribição 4.0.

Todo el contenido de esta obra, excepto donde se indique lo contrario, está bajo licencia de la licencia Creative Commons Reconocimento 4.0. 


\section{Os imunobiológicos na proteção da saúde: conhecendo sua história}

Edson Alves de Moura Filho

Os imunobiológicos foram e são essenciais para controle, eliminação e erradicação de algumas doenças e, por isso, exercem importante contribuição para o quadro de saúde pública mundial. Foram muitos os caminhos percorridos desde o surgimento da primeira vacina até se obterem todos os imunobiológicos hoje disponíveis às populações.

Neste capítulo, apresentaremos um pouco da história da descoberta, em ordem cronológica, de algumas das vacinas existentes, destacando o panorama epidemiológico da situação da varíola e da poliomielite antes da implantação da vacina, pelo seu caráter histórico como doença mais antiga da humanidade e por sua popularização (varíola e poliomielite, respectivamente). Nosso recorte considera aquelas vacinas que são utilizadas pelo Programa Nacional de Imunizações (PNI), incluindo uma em fase de implantação/desenvolvimento no Brasil, que é a vacina da dengue.

\section{Introdução}

Antes de iniciarmos a história dos imunobiológicos, é importante compreender o que é ou o que se entende por vacina e como geralmente é constituída.

Uma vacina é um preparado biológico de vírus ou bactérias que, ao ser administrado em um indivíduo, induz uma resposta imunitária protetora específica a um ou mais agentes infecciosos (http://WWw.vacinas.com.pt). São, portanto, produtos farmacêuticos compostos de agentes imunizantes, vírus ou bactérias, que se apresentam sob
A vigilância epidemiológica das doenças que levaram à descoberta das vacinas foi apresentada neste livro, no Capítulo7, "Vigilância das doenças imunopreveníveis".

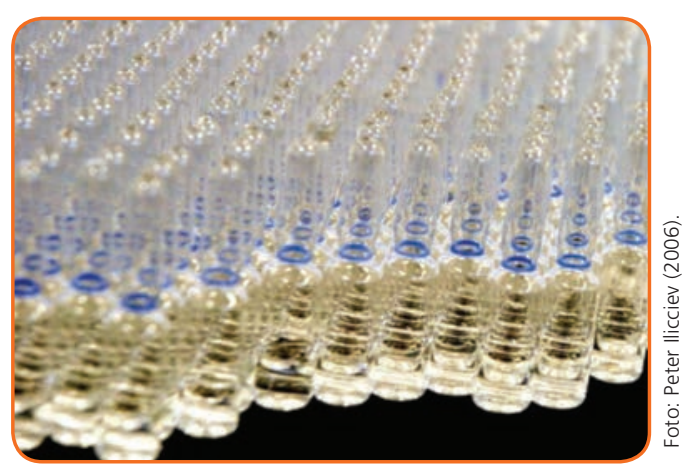

Uma das diversas formas de apresentação de vacinas. 
Informações detalhadas sobre as vacinas, sua composição e produção, bem como sobre sua atuação no organismo visando à imunidade são apresentadas no Capítulo 9, "Noções de imunologia: sistema imunológico, imunidade e imunização". diversas formas - bactérias ou vírus vivos, mortos, purificados ou modificados (BRASIL, 2013).

As vacinas, segundo seu modo de produção, podem se apresentar da seguinte forma:

* $\mathrm{O}$ vírus ou as bactérias (antígenos) produtores da doença são "mortos" por meio de processo químico, ou através do calor, dando origem às vacinas inativadas.

* Os vírus ou as bactérias são modificados por meio de um processo de múltiplos cultivos em laboratório, tendo como produto final vacinas vivas, ou seja, bactérias ou vírus que perderam sua capacidade de virulência (causar doenças), mas são capazes de induzir a resposta imunológica protetora para a(s) doença(s) contra a(s) qual(quais) a vacina está dirigida.

A vacina como produto final, além desses agentes, pode conter outros componentes, como líquido de suspensão, antibióticos etc., sendo as cepas iniciais, ou mesmo substâncias químicas acessórias utilizadas na elaboração das vacinas, padronizadas por instituições de referência da Organização Mundial da Saúde (OMS).

A produção de vacinas é feita por diversos fabricantes em vários países, incluindo-se o Brasil, e o laboratório produtor realiza o controle de qualidade desses produtos, a partir de critérios padronizados estabelecidos pela OMS.

\section{O início da história das vacinas: a vacina varíola}

A história da produção das vacinas se inicia no fim do século XVIII e se relaciona, diretamente, com o impacto que a varíola, uma das doenças mais antigas de conhecimento da humanidade, estava causando nas populações. Estima-se que cerca de 400 mil pessoas morreram no século XVIII em decorrência de infecção pela varíola, o que corresponderia a algo em torno de $8 \%$ a $20 \%$ de todas as mortes durante aquele século. Descobrir um meio de controlar a infecção por varíola era premente, e foi isso que motivou um médico inglês chamado Edward Jenner (1749-1823).

Em 14 de maio de 1796, Jenner encontrou a jovem leiteira, Sarah Nelms, com lesões recentes de varíola bovina nas mãos e nos braços. Ele já suspeitava que o pus das lesões poderia ter uma substância que protegia as tiradoras de leite de contrair uma forma mais grave da doença. 
Extraiu, então, a secreção das lesões de Sarah e a inoculou em um garoto de 8 anos de idade, James Phipps. Após essa primeira inoculação, Jenner passou a injetar, diariamente, uma pequena quantidade desse material em James, até que, finalmente, injetou o vírus da varíola, extraído de uma lesão recente de outro paciente que teve a doença. James apresentou febre branda e mal-estar, mas não desenvolveu a doença. Assim, Edward Jenner conseguiu provar sua teoria de que alguma substância no pus das lesões das tiradoras de leite protegia a pessoa de contrair a varíola. Sua descoberta causou muita resistência e enfrentou inúmeros preconceitos no mundo médico conservador da época.

A comunidade científica da época resistia em aceitar que um simples médico rural pudesse ter feito tamanha descoberta. Isso fez com que Edward Jenner fosse até humilhado publicamente, ao levar suas descobertas para Londres. Entretanto, como não se conseguiu negar o fato, finalmente a sua teoria foi aceita. Em 1840, o governo britânico determinou que o tratamento preconizado por Edward Jenner fosse a única forma utilizada para os casos de varíola.

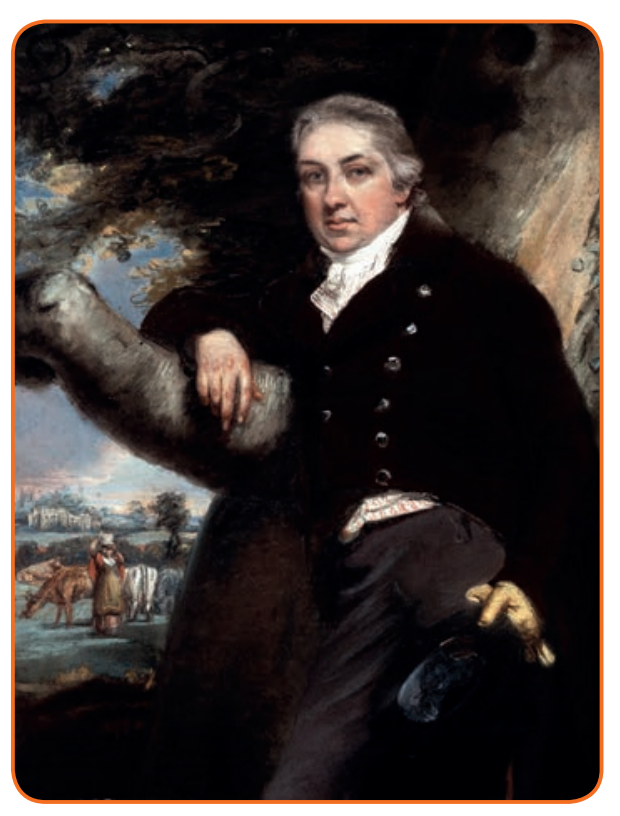

Retrato de Edward Jenner, pintado com óleo sobre tela por William Pearce.

Fonte: Wikimedia Commons.
No decorrer do tempo, realizaram-se várias tentativas de cultivar os vírus em laboratório (cultura do vírus), mas a produção da vacina da varíola só sofreu uma grande modificação com a introdução da técnica de cultivo de vírus em embrião de pinto. Mais tarde, ela passou a ser liofilizada, isto é, sua umidade é retirada, transformando-se numa pastilha e sendo reconstituída no momento da aplicação. Esse processo dá maior estabilidade à vacina.

No Instituto de Vacinas, em Paris, Lucien Camus (1885-1914) produziu vacina seca para a varíola em uma câmara a vácuo, removendo toda a umidade da amos- tra. Essas vacinas secas por ar foram usadas em áreas tropicais, onde a temperatura destruiria o material vacinal comum, dando origem ao método de liofilização. Entretanto, esse método não era muito adequado para a produção em larga escala, e a contaminação bacteriana era um problema frequente.
Por iniciativa própria, Edward Jenner não patenteou a descoberta, a fim de evitar que a vacinação se tornasse muito cara e de difícil alcance para toda a população.

Liofilizar é um processo em que uma desidratação (de tecido, sangue, soro ou outra substância) é produzida por meio de congelação brusca e, a seguir, alta pressão em vácuo, com o intuito de se manter a substância conservada por longo período de tempo. 
Tubo capilar é um tubo de vidro, semelhante ao de ensaio, mas muito menor. Tem esse nome porque só podem ser introduzidas no seu interior substâncias que ocupem muito pouco volume, semelhante ao de um capilar. É usado em experiências que envolvem grande precisão e rigor e que requerem quantidades microscópicas de substâncias (TUBO..., 2016).
No Brasil, a vacina cultivada em ovo embrionado foi implantada pelo então Instituto Oswaldo Cruz, que já dominava a tecnologia, usada na produção do imunizante para a febre amarela desde 1930.

Na evolução da vacinação contra a varíola, várias técnicas foram empregadas, tais como:

* escarificação (incisão na pele);

**essão múltipla (esfregar uma agulha paralelamente à pele);

* punção múltipla (várias picadinhas com uma agulha);

* broca (rodar um tubo capilar cortado com a vacina sobre a pele);

米injeção intradérmica e injetor.

Em 1959, a Organização Mundial da Saúde (OMS) decidiu pela realização de um programa global para a erradicação da varíola. Em 8 de maio de 1980, a 33ª Assembleia Mundial da Saúde acatou a recomendação da Comissão Global da OMS e declarou que "o mundo e todas as pessoas estavam livres da varíola" (WORLD HEALTH ASSEMBLY, 1999), estabelecendo, assim, o primeiro caso de erradicação global de uma doença. A partir desse fato, acredita-se que o vírus da varíola só exista confinado em dois laboratórios no mundo: na Rússia e nos Estados Unidos da América, apenas para uso em pesquisas e, também, como uma fonte para a produção da vacina, caso haja ressurgimento da moléstia.

\section{Vacina raiva humana}

Na sequência cronológica, verificamos que, para a descoberta da vacina contra a raiva humana, foi utilizada a mesma linha de raciocínio científico adotada na da varíola. Em 6 de julho de 1885, chegou ao laboratório de Louis Pasteur um garoto alsaciano de 9 anos de idade, Joseph Meister, que havia sido mordido por um cão raivoso. Pasteur, que vinha desenvolvendo pesquisas sobre atenuação do vírus da raiva, injetou na criança um material infectado com o vírus da raiva. Foram realizadas várias inoculações, e Meister não chegou a contrair a doença (TIMELINES..., 2016).

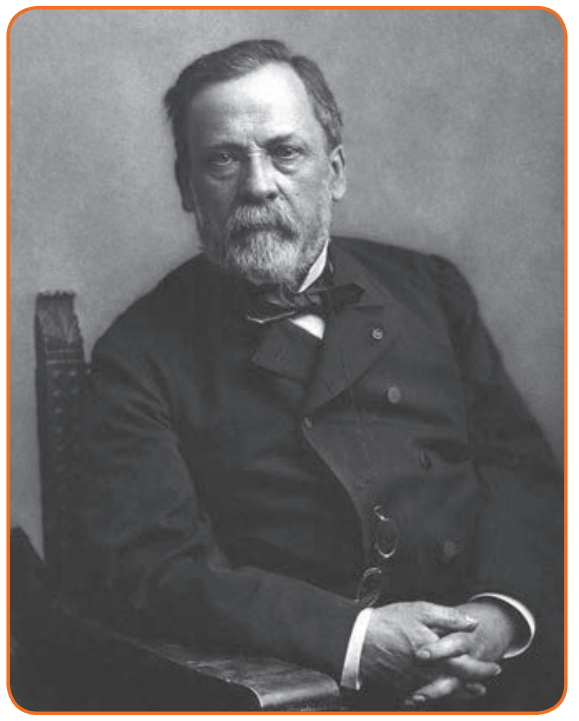

Louis Pasteur (1822-1895), importante cientista francês.

Fonte: Wikimedia Commons. 
Em 26 de outubro de 1889, Pasteur comunicou à Academia de Ciências da França a descoberta do imunizante para a raiva, denominando-o de vacina em homenagem a Edward Jenner, uma vez que ele foi o criador da primeira vacina utilizando o vírus vaccínia.

\section{Descoberta das toxinas: vacina DT (difteria e tétano) e DTP (difteria, tétano e coqueluche [pertussis])}

Em 1888, Emile Roux (1853-1933) e Alexander Yersin (1863-1943) demonstraram que o bacilo da difteria (Corynebacterium diphtheriae) produzia uma toxina poderosa, responsável pelo quadro da doença. Em 1891, Emil von Behring (1854-1917) injetou em cobaias doses subletais dessa toxina, provocando o aparecimento de moléculas antitóxicas. A pesquisa inicialmente utilizou carneiros, cabras, cães e, finalmente, cavalos, que se mostraram mais eficientes na produção de antitoxinas. Essas moléculas antitóxicas eram capazes de proteger o indivíduo da infecção e de ser transferidas para outros animais, tornando-os imunes à difteria.
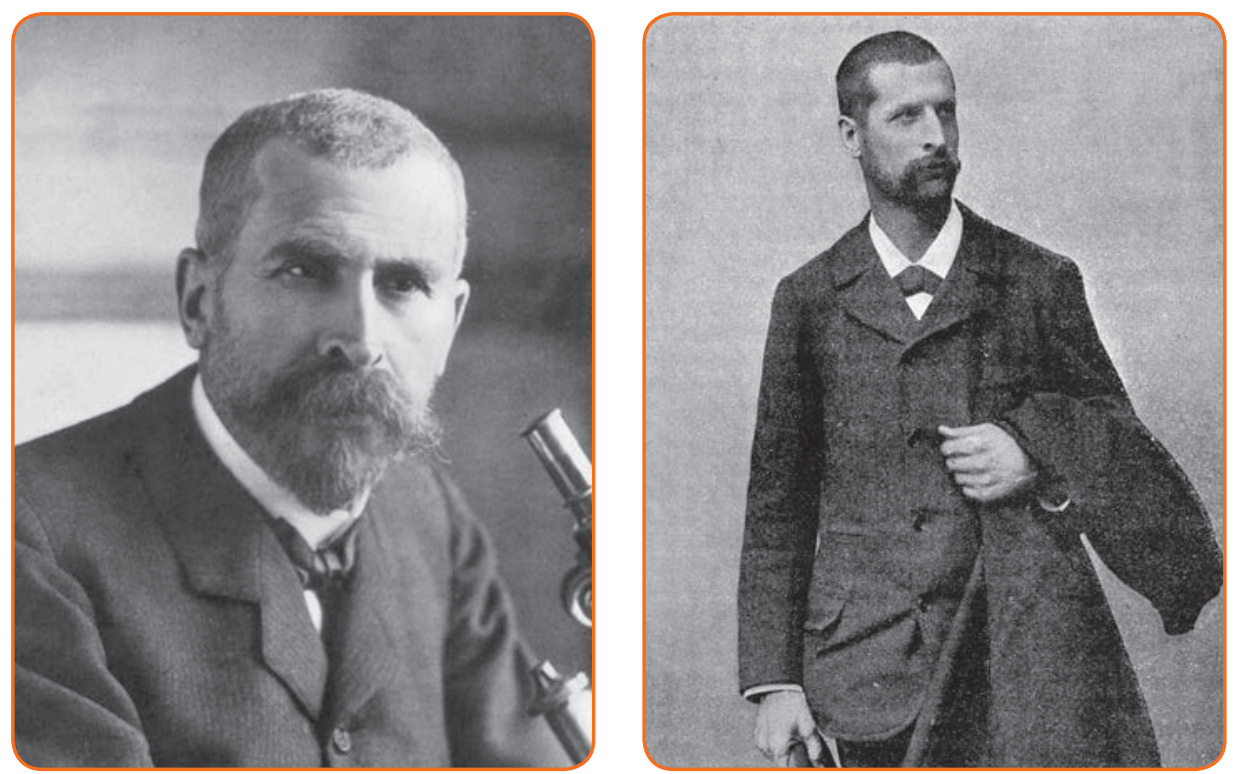

Pierre Emile Roux (1853-1933), à esquerda, e Alexander Yersin (1863-1943), à direita.

Fonte: Wikimedia Commons. / Fonte: Welcome Images.

Na década de 1990, em Berlim, Kitasato Shibasaburō (1853-1931) e von Behring mostraram que os produtos do sangue dos porcos da Guiné (o soro) continham uma substância que evitava os efeitos danosos do $C$. diphtheriae e de sua toxina.
Emile Roux foi um médico bacteriologista e imunologista francês. Alexander Yersin foi um bacteriologista suíço que ficou bastante conhecido por ter descoberto o bacilo da peste (Yersinia pestis). Emil von Behring foi um médico alemão que deu grande contribuição para os estudos sobre imunologia de doenças bacterianas; em 1891, ganhou o Prêmio Nobel de Medicina pelo seu trabalho sobre a difteria.

Dose subletal é uma dose de uma substância potencialmente letal que não é suficientemente grande para causar a morte. A dose letal da toxina da difteria para humanos é de cerca de 0,1 $\mu \mathrm{g}$ de toxina por $\mathrm{kg}$ de peso corporal.

Em 1901, von Behring ganhou o primeiro Prêmio Nobel de Medicina por seu trabalho sobre a difteria. 
Soroterapia é o tratamento que utiliza soro obtido de organismo imunizado. Tem a finalidade de combater uma doença específica (no caso de moléstias infecciosas), ou um agente tóxico específico (venenos ou toxinas).

A vigilância epidemiológica da difteria foi abordada no Capítulo 7, "Vigilância das doenças imunopreveníveis". Já soroterapia e tipos de soro existentes serão abordados com detalhes no próximo capítulo.

Toxoide é a toxina inativada, capaz de manter seu potencial imunizante, sem causar a infecção.

Você sabia?

A vacina DTP foi o primeiro imunobiológico no mundo a imunizar contra mais de um microrganismo.
BCG é a sigla de Bacillus CalmetteGuérin, ou vacina tuberculose, obtida da bactéria Mycobacterium bovis em estado atenuado, ou seja, enfraquecido. O BCG começou a ser utilizado como vacina, no Brasil, em 1925, e passou a fazer parte do conjunto de imunizantes do PNI desde o momento de sua criação.
Em seguida, demonstraram que poderiam curar a difteria em um animal injetando-lhe o soro de outro imunizado. Eles denominaram a substância de antitoxina, e o tratamento recebeu a denominação de soroterapia.

Em 1904, os imunologistas von Behring, Loewenstein (1891-1973) e Alexander Thomas Glenny (1882-1965), continuando a linha de trabalho de Kitasato e von Behring, (TIMELINES..., 2016) demonstraram que as toxinas poderiam ser inativadas por substâncias químicas, no caso, o formol, mantendo seu potencial imunizante, mas sem causar infecção. Essa descoberta levou ao desenvolvimento dos primeiros toxoides: diftérico e tetânico.

Em 1948, a primeira vacina combinada para o tétano e a difteria foi disponibilizada nos Estados Unidos. Em 1949, os toxoides tetânico e diftérico e o imunizante para a coqueluche foram reunidos numa única vacina: tríplice bacteriana, ou DTP. Em meados de 1990, o componente Pertussis foi substituído pela versão acelular (DTPa), que resultou em menos reações adversas.

\section{Vacina $B C G$}

A tuberculose, doença de forte impacto e de distribuição mundial, se constitui em importante problema de saúde pública por causar elevado número de óbitos e complicações. Estudos referem que a tuberculose infecta cerca de $30 \%$ da população de todo o mundo (BOLETIM EPIDEMIOLÓGICO, 2015). O advento da vacina, no início do século XX, contribuiu para o declínio do número de óbitos.

Em 1909, Albert Calmette (1863-1933) e Camille Guerin (1872-1961), do Instituto Pasteur, comunicaram à Academia de Ciências Francesa o desenvolvimento de uma bactéria do tipo bacilo com virulência atenuada, proveniente de sucessivas culturas em bile de boi. Esse bacilo atenuado apresentava capacidade imunizante para a tuberculose: era o BCG, que, após uma série de testes, passou a ser regularmente utilizado como vacina. 

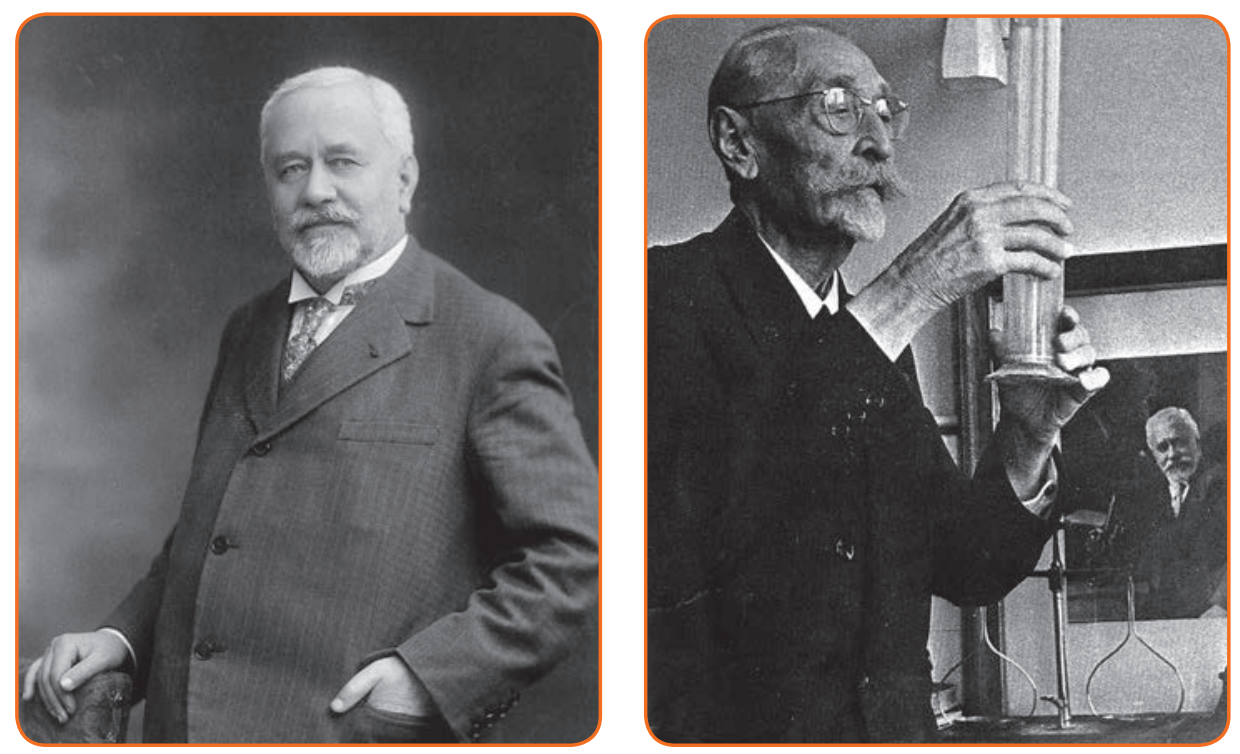

Albert Calmette (1863-1933), à esquerda, e Jean Marie Camille Guerin (1872-1961), à direita. Fonte: Welcome Images.

\section{Vacina febre amarela}

Em 1936, na descoberta da vacina da febre amarela, Max Theiler (1899-1972) e Dr. Hugh Hollingsworth Smith (1902-1995) (TIMELINES..., 2016), da Fundação Rockefeller, identificaram a cepa 17D da febre amarela, um vírus atenuado por passagens em cérebro de ratos e em embrião de galinha. No ano seguinte, a vacina foi testada, pela primeira vez, no Brasil (BRASIL, 1989).

Os testes realizados no Brasil demonstraram que doses de vírus muito altas não eram mais eficazes do que doses relativamente pequenas, desde que a pessoa fosse inoculada sob a pele e com vírus suficientemente ativo.

Ainda não havia dados sobre a duração da imunidade proporcionada pelo vírus 17D. Em 1940, a Fundação Rockefeller, em cooperação com o Serviço Nacional de Febre Amarela, escolheu uma região considerada livre da febre amarela para estudar essa questão. Em 1958, no ano em que se erradicou o Aedes aegypti no Brasil, foram feitos novos testes em Pouso Alegre, Minas Gerais, para verificar quanto tempo durava a imunidade conferida pela vacina (FERREIRA, 2011).

Desde o fim da década de 1930, a vacina para a febre amarela vem sendo fabricada pelo Instituto de Tecnologia

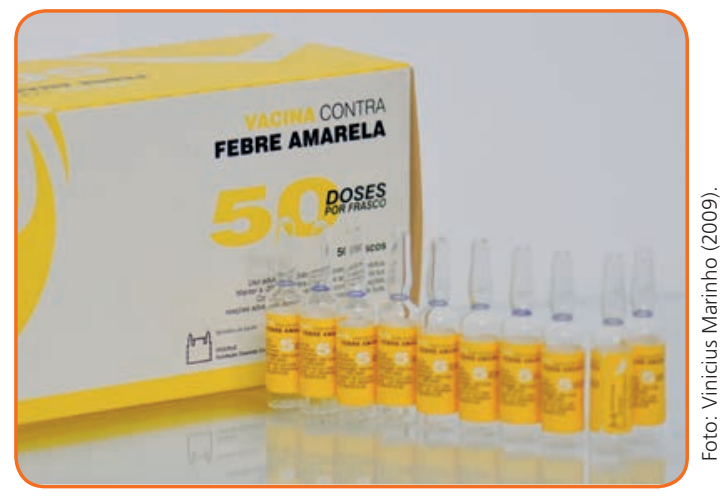

Vacina febre amarela produzida por Bio-Manguinhos, Fundação Oswaldo Cruz. 
Coqueluche, também chamada tosse convulsa, é uma doença altamente contagiosa causada pela bactéria Bordetella pertussis, ou Bordetella parapertussis, que causa tosse incontrolável e violenta.
Antes de 1933, pensava-se que uma bactéria denominada Haemophilus era a causadora da influenza. em Imunobiológicos (Bio-Manguinhos), da Fundação Oswaldo Cruz (Fiocruz). Hoje, a Fiocruz é responsável por $80 \%$ da produção mundial desse imunizante.

\section{Vacina coqueluche}

Em 1939, a bacteriologista americana Pearl Kendrick (1890-1980) e sua colega, Grace Elderding (1900-1988), do Departamento de Saúde Pública de Michigan, publicaram os resultados do estudo sobre a vacina para coqueluche. Os estudos demonstraram efetividade da vacina e se tornaram ponto de referência em relação à doença. Atualmente, o componente pertussis (da coqueluche) encontra-se em várias vacinas: DTP, DTPa, dTpa, DTPHib (tetravalente), DTPHib HepB (pentavalente), DTPHib HepB Pólio (hexavalente).

\section{Vacina influenza}

No início do século XX, a influenza era uma doença com forte impacto na população. Em 1918-1919, o mundo enfrentou uma pandemia que, pelo alto número de mortes ocorridas na Espanha, recebeu a denominação de Pandemia Influenza Espanhola, tendo causado cerca de 50 milhões de mortes no mundo. Estima-se que, atualmente, a doença cause de três a cinco milhões de casos e 250 mil a 500 mil mortes no mundo a cada ano.

Em 1933, pesquisadores descobriram que os vírus influenza tipos A, B e raramente o C causam a doença. Em 1938, Thomas Francis (1900-1969) e Jonas Salk (1914-1995) desenvolveram a primeira vacina contra os vírus influenza. A primeira vacina foi usada para proteger as forças militares americanas contra a influenza durante a Segunda Grande Guerra.

A influenza é um problema de saúde pública no Brasil. Essa patologia pode levar a complicações graves e óbito, especialmente nos grupos de alto risco para as complicações da infecção viral (crianças

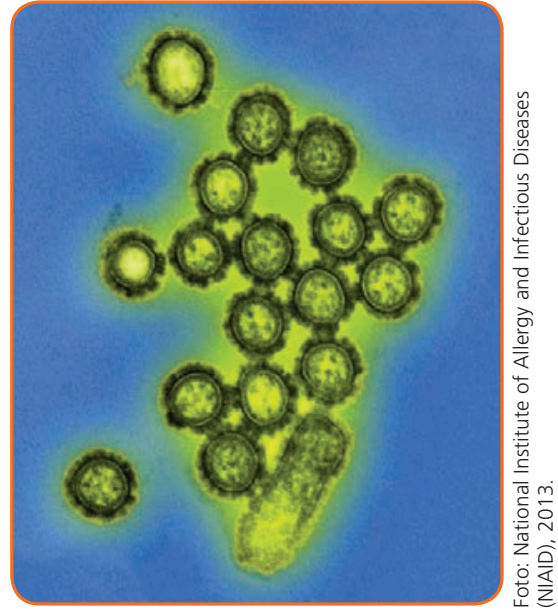

Micrografia de vírus influenza H1N1 colorida digitalmente.

Fonte: Wikimedia Commons. menores de 5 anos de idade, gestantes, adultos com 60 anos ou mais, portadores de doenças crônicas não transmissíveis e outras condições clínicas especiais). A principal intervenção preventiva para esta doença é a vacinação. 
O Programa Nacional de Imunizações no Brasil introduziu a vacina influenza em 1999, e, a partir desse ano, vem se registrando um impacto na redução das internações hospitalares, dos gastos com medicamentos para tratamento de infecções secundárias e de mortes evitáveis (BRASIL, 2009).

\section{Vacina pneumococo}

O Streptococcus pneumoniae (pneumococo) é uma bactéria que afeta crianças e adultos em todo o mundo. A doença é transmitida de pessoa a pessoa. É uma importante causa de doença em crianças pequenas e de letalidade em idosos e pessoas que sofrem de outras enfermidades.

Até 1937, a doença pneumocócica era capaz de levar à morte, praticamente, todas as pessoas infectadas pelo pneumococo. Alguns quimioterápicos descobertos naquela época foram capazes de diminuir um pouco essas taxas, mas uma redução importante da mortalidade só ocorreu na década de 1940, após a descoberta da penicilina para uso em humanos (BITTENCOURT, 1945).

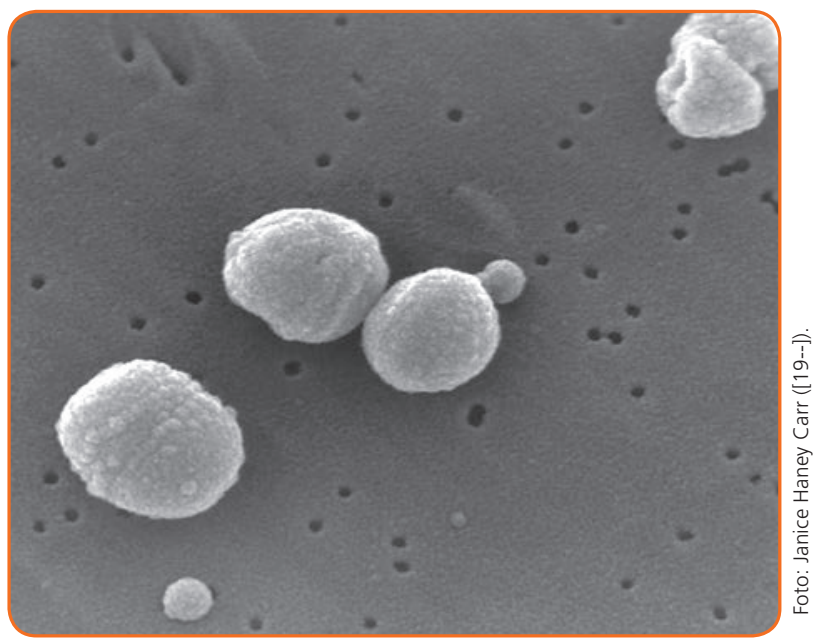

Micrografia mostrando a bactéria Streptococcus pneumoniae. Fonte: Public Health Library of Images, CDC.
Em 1945, foi introduzida uma vacina tetravalente para o pneumococo, mas ela não foi amplamente utilizada pela crença na efetividade do uso da penicilina, sendo retirada do mercado na década de 1950.

Embora muito relevante, o que se descobriu, a partir de estudos em quantitativos maiores de pessoas acometidas com o pneumococo, foi que a penicilina dava uma grande contribuição, mas não evitava a mortalidade em muitos dos casos de infecção.

A história da vacina pneumocócica começa com Robert Austrian, MD (1916-2007), diretor de pesquisa médica da Universidade da Pensilvânia. Ele estava convencido e defendia (com base nas observações que realizava de pacientes infectados com pneumococo) que a disponibilidade de antibióticos para tratar infecções pneumocócicas não era razão suficiente para abandonar a pesquisa da vacina para o pneumococo. Estava convicto de que a vacina era decisiva como medida de prevenção.

Austrian estudou o pneumococo em toda a sua vida acadêmica. Na década de 1970, ele resgatou a produção da vacina que havia sido veiculada na década de 1940. No entanto, um novo desafio se apresentou:
O Streptococcus pneumoniae, ou pneumococo, é uma bactéria que tem 90 sorotipos imunologicamente distintos, de importância epidemiológica mundial. Por ser uma bactéria, é combatido com a penicilina (um antibiótico derivado de fungos do gênero Penicillium), capaz de desencadear uma resposta positiva no tratamento da doença.

A descoberta da penicilina (1928), por Alexander Fleming, e sua posterior possibilidade de uso em humanos (1941) representaram uma revolução na história da medicina (DOENÇA..., 2014). 
Maurice Hilleman foi um virologista que deu uma grande contribuição para a história das vacinas, tendo participado da produção de mais de 40 vacinas, incluindo as de sarampo, caxumba, hepatite $A$, hepatite $B$, meningite, pneumococo, Haemophilus influenzae e rubéola.

Robert Austrian o procurou quando atuava como encarregado de vacinas na Merck, uma das maiores farmacêuticas do mundo, para produção da vacina para pneumococo (NEWMAN, 2005; WEISER; ROBBINS, 2013).

Cápsula externa - A estrutura do pneumococo conta com uma cápsula externa que é formada de polissacarídeos (açúcares). Os polissacarídeos são capazes de induzir imunidade, e, por isso, a PCV é construída usando a cápsula que contém essas moléculas. No entanto, a vacina não induz memória imunológica duradoura, nem é eficaz em crianças menores de 2 anos de idade. a produção de uma vacina para o pneumococo que envolvia determinar qual dos mais de 90 tipos da bactéria pneumocócica produzia a maioria dos casos da doença. Observando pacientes, o médico identificou diferentes cepas da bactéria pneumocócica, encontrando eventualmente dezenas de sorotipos. Uma vez concluído o trabalho, ele isolou os tipos mais apropriados para a vacina e forneceu essa informação a Maurice Hilleman (1919-2005). Os pesquisadores do laboratório Merck então desenvolveram a vacina da cápsula externa polissacarídica da bactéria, a PCV, ou seja, vacina polissacarídea conjugada, que, de acordo com o número de sorotipos, receberá a denominação PCV mais a quantidade de sorotipos (por exemplo, PCV7, PCV13).

Em 1976, Hilleman relatou que a vacina do pneumococo, por ele desenvolvida, era segura e efetiva em ensaios clínicos realizados. Em 1977, o Laboratório Merck lançou a vacina com proteção para 14 sorotipos; em 1983, expandiu seu trabalho, produzindo uma vacina para 23 tipos de bactéria pneumocócica.

Embora a vacina polissacarídica de Robert Austrian para a doença pneumocócica fosse efetiva para adultos, ela não gerava imunidade consistente em crianças com menos de 2 anos de idade, como já mencionado, nem em indivíduos com certas imunodeficiências, como a infecção pelo HIV.

Em fevereiro de 2000, surgiu uma nova vacina conjugada: a PCV7, que protegia contra sete sorotipos de pneumococos. Os ensaios clínicos mostraram sua efetividade em crianças menores de 2 anos de idade, e foi recomendada para todas as crianças de 2 a 23 meses de vida. No entanto, em junho de 2004, um estudo populacional publicado no Jornal Americano de Saúde Pública relatou que "evidências preliminares mostram que, no curto período do estudo, o uso da PCV7 é correlacionado com a diminuição de alta hospitalar por doença pneumocócica invasiva" (RAMANI et al., 2004). Isso quer dizer que a PCV7 não estava contribuindo positivamente para a cura dos casos da doença; por isso, outra vacina foi desenvolvida, a PCV13, e a partir de sua liberação, em 2010, vem substituindo a PCV7.

A partir de março de 2010, o Programa Nacional de Imunizações brasileiro introduziu, no calendário básico de vacinação, a PCV 10 (contra os sorotipos 1, 4, 5, 6B, 7F, 9V, 14, 18C, 19F e 23F), mediante acordo de transferência de tecnologia para a Fundação Oswaldo Cruz, garantindo, assim, a sustentabilidade da vacinação no país. A decisão de se utilizar rotineiramente a vacina PCV10, em detrimento da PCV13, se dá em função do custo, que é muito alto para ser implantado na rede 
pública, e, também, por se necessitar de estudos mais amplos sobre seu custo-efetividade.

Atualmente, a emergência da doença causada por sorotipos de pneumococos não incluídos nas várias formulações de vacinas abastece a pesquisa para maximizar a proteção contra mais de 90 sorotipos conhecidos de pneumococos (NEWMAN, 2005; WEISER; ROBBINS, 2013).

\section{Vacina sarampo}

O período de 1950 a 1960 foi fundamental nas pesquisas com vacinas. Em 1958, o especialista em doenças infecciosas, Samuel L. Katz, MD (1927-) juntamente com Thomas C. Peebles (1921-2010) e outros pesquisadores do William A. Hinton State Laboratory Institute, Boston, Massachussetts testaram a primeira versão da vacina laboratorial para o vírus do sarampo em crianças de uma escola fora de Boston. Dos 11 vacinados que desenvolveram anticorpos para o sarampo, nove apresentaram um exantema leve. Os pesquisadores perceberam que o vírus tinha de ser mais enfraquecido (TIMELINES...,2016).

Em 1962, Maurice Hilleman (o mesmo das vacinas para encefalite japonesa e pneumococo) e colegas desenvolveram uma vacina atenuada do sarampo por 80 passagens da cepa viral de John Enders (1897-1985) em diferentes tipos de células. A vacina resultante, Rubeovax, foi administrada com uma dose de gamaglobulina para reduzir as reações, principalmente febre e exantema.

No ano seguinte, após a demonstração de sua segurança e eficácia em macacos, inicialmente, e, depois, em humanos, John Enders e colegas declararam sua vacina capaz de prevenir a infecção. Sua cepa Edmonston-B do vírus do sarampo foi transformada em vacina licenciada nos EUA.

Em 1968, o laboratório Merck iniciou a distribuição de uma vacina desenvolvida por Maurice Hilleman e colegas, aperfeiçoada da cepa de Enders. Hilleman eliminou a necessidade da aplicação de gamaglobulina com a vacina, passando o vírus em células de embrião de galinha por 40 vezes, enfraquecendo-o mais. Denominada de cepa Moraten (More Attenuated Enders, em português: Enders mais atenuada), esta é a única vacina usada nos EUA, desde a sua liberação, como também é a única cepa utilizada no Brasil.

\section{Vacina hepatite B}

Em 1965, o médico e pesquisador americano Baruch Blumberg (19252011 ) descobriu a imensa diversidade de anticorpos no sangue através
Gamaglobulina é um concentrado de anticorpos cuja função é proporcionar as defesas, de forma imediata, para prevenir uma enfermidade em particular. As primeiras vacinas, por sua composição e concentração, provocavam alguns efeitos colaterais. 
do isolamento de proteínas. Um dos mais fantásticos de seus achados foi um anticorpo em um hemofílico que tinha recebido muitas transfusões sanguíneas e que reagiu com o soro de um aborígene australiano. Essa proteína encontrada no sangue do aborígene australiano foi intitulada antígeno de superfície do vírus da hepatite B (HBsAg), denominado antígeno Austrália.

O antígeno Austrália circula no sangue de pessoas previamente infectadas com hepatite não apenas como parte do vírus, mas também como uma pequena partícula independente. Blumberg e outros pesquisadores foram capazes de conectar essa presença do antígeno com a infecção da hepatite B. Tratava-se da proteína de superfície do vírus da hepatite B. Posteriormente, relacionaram a infecção pelo vírus da hepatite B ao câncer de fígado.

A descoberta do antígeno Austrália teve um importante efeito no estudo da hepatite $\mathrm{B}$, em grande parte porque o vírus não pode ser cultivado em laboratório. Dessa forma, tal antígeno serve como modelo para o vírus e é uma fonte para produção da vacina (TIMELINES...,2016).

No ano de 1981, o Food and Drug Administration (Departamento de Administração de Drogas e Alimentos dos EUA-FDA) licenciou a vacina hepatite B, Heptavax-B, derivada de sangue humano. Foi a primeira vacina de subunidade viral desenvolvida.

Hilleman foi o responsável pelo desenvolvimento da Heptavax-B. Ele transformou o antígeno Austrália em uma vacina efetiva obtendo o antígeno a partir do soro de usuários de droga endovenosa e de homossexuais masculinos, nos quais a doença era mais frequentemente presente.

A vacina se mostrou efetiva na prevenção da hepatite $B$, mas, em virtude das preocupações com a infecção pelo HIV, ela foi substituída, em 1986, por um produto que não usava soro humano. Essa nova ação produziu a primeira vacina com tecnologia recombinante (modificado pelo homem); nesse caso, foram utilizadas as células de levedura, de forma que elas produzissem a proteína, que é o ingrediente ativo na vacina atual da hepatite B.

\section{Vacina rubéola}

A sigla MMR representa a

abreviação dos termos em inglês:

Measles, Mumps, Rubella.
A primeira vacina rubéola, viva, atenuada, desenvolvida por Maurice Hilleman, usando o vírus da rubéola obtido da Divisão de Padrões Biológicos, foi licenciada em 1969. Em 1971, essa vacina foi incorporada à formulação da vacina combinada sarampo-caxumba-rubéola (MMR). 
Em 1979, uma vacina rubéola melhorada, desenvolvida por Stanley A. Plotkin, suplantou a vacina de Hilleman nos Estados Unidos. Esta vacina, a RA27/3, foi usada na Europa por anos e oferecia proteção superior contra a doença. Ela substituiu a vacina rubéola original na MMR e ainda é usada atualmente.

A vacina MMR (tríplice viral) contendo a cepa Plotkin faz parte do calendário vacinal do PNI (TIMELINES..., 2016).

\section{Vacina contra o HPV}

Escritos da Grécia Antiga já faziam referência às verrugas genitais que comprometiam a pele em várias regiões; elas tinham a denominação de Ficus, Thymus, Thimion ou Condyloma acuminatum. Somente em meados do século XIX, começou-se a sugerir que as verrugas genitais poderiam estar relacionadas ao contato sexual. A hipótese diagnóstica de condilomas acuminados, um tipo de verruga, até a década de 1970, era somente ventilada quando havia presença de lesões observáveis a olho nu, que comprometessem os genitais externos (DORES, [2005]).

Na década de 1970, foi reconhecido que algum tipo de doença sexualmente transmissível estava relacionado ao câncer cervical e que as mulheres com câncer apresentavam, frequentemente, herpes genital.

Estudos demonstraram que o vírus HPV (human papilomavirus, em português papilomavírus humano) estava associado à presença do câncer de colo de útero. Estima-se que metade das mulheres, na faixa etária de 35 a 55 anos, com diagnóstico desse tipo de câncer, foi exposta na adolescência ao HPV por meio de relações sexuais com parceiro infectado (SÃO PAULO, 2014, p. 1).

O virologista alemão Harald zur Hausen (1936-), em trabalho conjunto com Lutz Gissmann (1949-), isolou, em 1976, o vírus HPV a partir da centrifugação de verrugas genitais. Harald propôs que o HPV, e não o herpes, era a causa do câncer cervical. Em 1983 e 1984, zur Hausen descobriu o DNA do HPV em tumores de câncer cervical, provando sua teoria.

A partir dessa constatação, os pesquisadores em todo mundo iniciaram a pesquisa de vacinas para duas cepas do HPV, mais vinculadas ao câncer, desenvolvendo a vacina Cervarix (contra os tipos 16 e 18 do HPV). Posteriormente, foi elaborada a vacina quadrivalente contra os HPVs tipos 6, 11, 16 e 18, mais prevalentes na população brasileira (SÃO PAULO, 2014, p.1).
A cepa RA 27/3 é de vírus vivos e atenuados, utilizada na produção da vacina contra a rubéola. 
Lactentes e crianças jovens são o maior grupo de risco para infecção por Hib, por isso a importância de se testar a vacina nessa faixa etária.
O Programa Nacional de Imunizações no Brasil introduziu, a partir de 2014, a vacina HPV quadrivalente (HPV tipos 6, 11, 16 e 18), tendo como alvo as meninas de 11 a 13 anos de idade (2014) e 9 a 11 anos de idade (2015).

\section{Vacina Haemophilus influenzae tipo b}

Haemophilus influenzae (Hi) é uma bactéria responsável por significativa morbidade e mortalidade em todo o mundo, especialmente em crianças com menos de 5 anos de idade. Existem vários tipos de Hi; no entanto, a doença grave é causada, principalmente, pelo Hi tipo b (Hib).

Em 1985, a primeira vacina para Haemophilus influenzae tipo b (Hib) foi licenciada nos Estados Unidos. Os pesquisadores que a desenvolveram, Porter W. Anderson (1937-) e David H. Smith (1932-1999), tinham iniciado os trabalhos em 1968, na extração e purificação da camada externa polissacarídica da bactéria. Um teste da vacina de 1975, na Finlândia, mostrou que as crianças, mas não todos os lactentes, produziram uma resposta protetora à bactéria. A falta de interesse das companhias farmacêuticas na fabricação da vacina levou Smith a fundar uma empresa para produzi-la (TIMELINES...,2016).

A vacina polissacarídica de Smith foi suspensa em 1988, quando os cientistas americanos John Bennett Robbins (1932-) e Rachel Scheerson (1932-) conseguiram produzir a primeira vacina conjugada do Haemophilus influenzae (Hib). As vacinas conjugadas são mais capazes de induzir uma resposta imunológica que as vacinas polissacarídicas em lactentes e crianças jovens.

A introdução da vacina conjugada para Hib produziu grande declínio no número de casos de doença invasiva por Hib nos diversos países em que seu uso foi incorporado à rotina de vacinação das crianças. No entanto, houve o ressurgimento de casos com doença invasiva por Hib, o que tem mobilizado vários investigadores na busca das possíveis explicações para esses eventos, bem como na identificação das medidas a serem implementadas para evitar o reaparecimento da doença.

Em 1999, a Hib foi introduzida no Brasil e, em 2003, a vacina passou a ser oferecida nas unidades básicas de saúde, em combinação com a DPT - vacina tetravalente (DPT+Hib). 


\section{Vacina febre tifoide}

A febre tifoide é uma doença de distribuição mundial. Sua vacina foi desenvolvida em 1975, a partir de uma cepa atenuada da bactéria Salmonella enterica typhi. Era uma vacina viva, atenuada, oral, liberada nos EUA em dezembro de 1989. Em novembro de 1994, surgiu uma vacina injetável. Essa vacina era feita de bactéria inteira morta e conhecida pelas reações no local da injeção (TIMELINES..., 2016).

A ocorrência da doença está diretamente relacionada às condições de saneamento existentes e aos hábitos individuais. Estão mais sujeitas à infecção as pessoas que habitam ou trabalham em ambientes com precárias condições de saneamento.

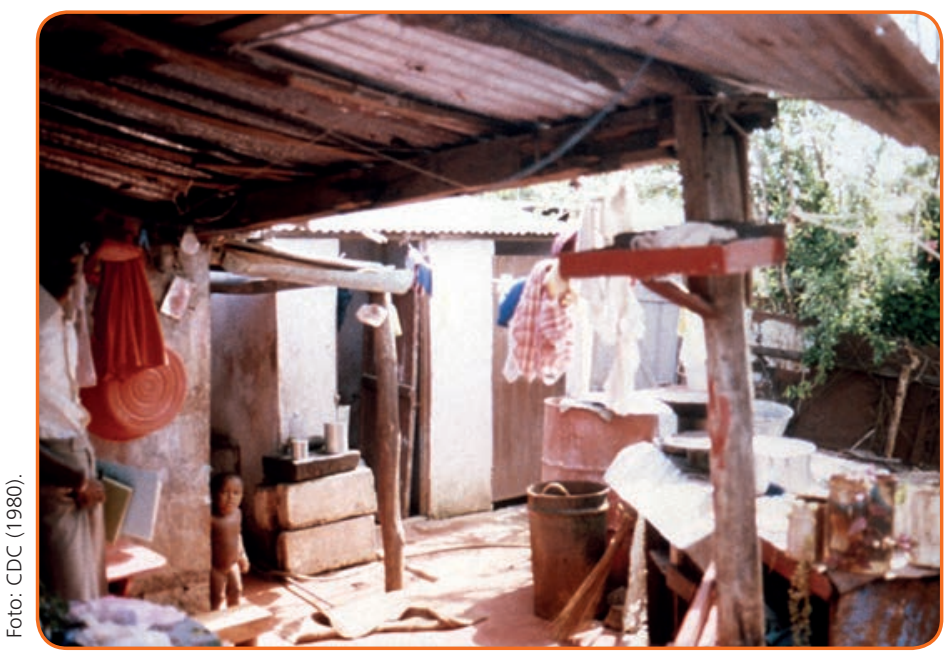

Condições precárias de saneamento e higiene são fatores que favorecem o desenvolvimento de febre tifoide. Na foto, a casa apresentada foi identificada como caso-índex de um surto de febre tifoide nas ilhas Maurício, em 1980 (PHIL/ CDC, id\#6457).
Atualmente, estão disponíveis duas vacinas febre tifoide de nova geração: a vacina polissacarídica, que é administrada por injeção, está indicada a partir de 2 anos de idade, e a vacina viva atenuada, de uso oral, indicada a partir de 5 anos.

Ambas estão indicadas, apenas, para indivíduos sujeitos à exposição excepcional, como os trabalhadores que entram em contato com esgotos; para aqueles que ingressem em zonas de alta endemicidade, por ocasião de viagem; e para quem vive em áreas onde a incidência é comprovadamente alta. Com a exceção de recrutas, não há recomendação atual da vacina contra a febre tifoide em massa ou rotineiramente em populações circunscritas (BRASIL, 2014).

\section{Vacina rotavírus}

Em 1998, o laboratório Wyeth Pharmaceuticals lançou a primeira vacina do rotavírus, a RotaShield, que era oral atenuada tetravalente. Em 15 de outubro de 1999, por sua associação com a ocorrência de intussuscepção intestinal, a vacina foi retirada do mercado (TIMELINES..., 2016).

Para substituí-la, o laboratório GlaxoSmithKline lançou a vacina Rotarix, e o Merck, a RotaTeq, ambas de vírus humano atenuado. Em março de 2010, cientistas descobriram um vírus de porco na vacina Rotarix,
A ocorrência da doença diminui com a idade. Nas últimas décadas, observa-se uma tendência de declínio nos números de casos e de morte (BRASIL, 2014).

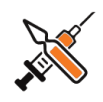

A OMS recomenda a aplicação da vacina contra a febre tifoide apenas nas áreas em que a doença é endêmica.
Intussuscepção, também chamada de intuscepção, consiste na entrada de um segmento de órgão oco em outra parte do mesmo órgão. A porção invaginada recebe o nome de intussuscepto e a parte do órgão que invagina a outra é chamada de intussusceptiente. Ocorre mais frequentemente em órgãos que possuem ampla motilidade, como o intestino delgado e o cólon (MELDAU, 2006). 
Eventos adversos pós-vacinação é um tema abordado no Capítulo 3, "Vigilância epidemiológica em eventos adversos pós-vacinação", do livro Rede de Frio: gestão, especificidades e atividades (SILVA; FLAUZINO, 2016) fato que consideraram um problema significativo e que determinou a suspensão desta. Outros estudos mostraram fragmentos de vírus de porco na vacina RotaTeq, que também foi suspensa. No entanto, os vírus de porcos não infectam o homem e, certamente, estiveram presentes nas vacinas durante os testes clínicos iniciais, pois ambas eram derivadas de um dos processos químicos usados para preparar as células para crescimento das cepas do rotavírus vacinal.

Nenhum evento adverso foi associado aos materiais do vírus do porco nas vacinas. Com essas considerações, as vacinas obtiveram o apoio do Food and Drug Administration (FDA), em 14 de maio de 2010, e voltaram à comercialização, bem como estão sendo utilizadas pelo PNI.

A vacina é utilizada na prevenção de gastroenterites causadas por rotavírus, o qual infecta o estômago e intestino, sendo causa comum de diarreia grave em criança. Os menores de 5 anos de idade, especialmente aqueles entre 6 meses e 2 anos, são mais vulneráveis à doença. $\mathrm{O}$ vírus é muito resistente no ambiente e pode sobreviver por meses nas fezes em temperatura ambiente, sendo fundamental a adoção da estratégia de vacinação (ROTAVIRUS, 2016).

\section{Vacina poliomielite}

Considerando-se o histórico apresentado, nenhum imunizante contribuiu tanto para a popularização das vacinas como o da poliomielite. Conhecida desde a Antiguidade, a doença passou a assumir importância como problema de saúde pública no fim do século XIX, ao irromper de forma epidêmica nos Estados Unidos da América e na Europa.

A história da doença tem início em 1789, quando o físico britânico Michael Underwood descreveu, pela primeira vez, a pólio, referindo-se a ela como "debilidade das extremidades inferiores" (GLOBAL POLIO ERADICATION INITIATIVE, 2010; TIMELINES..., 2016).

Em 1840, o físico alemão Jacob von Heine (1800-1879) publicou uma monografia de 78 páginas descrevendo as características clínicas da doença e afirmando que os sintomas sugeriam o envolvimento da medula espinhal (GLOBAL POLIO ERADICATION INITIATIVE, 2010; TIMELINES..., 2016).

Com a identificação do vírus, em 1908, por Karl Landsteiner (18681943) e Erwin Popper (1879-1955), médicos austríacos, a doença passou a ser notificável. Naquele mesmo ano, o médico americano Simon Flexner (1863-1946) induziu a infecção pelo vírus da pólio em macacos, 
facilitando, assim, as oportunidades de pesquisa (GLOBAL POLIO ERADICATION INITIATIVE, 2010; TIMELINES..., 2016).

Em 1935, os médicos Maurice Brodie (1903-1939) e John Kollmer (1886-1962) tentaram desenvolver a primeira vacina pólio, porém os testes de campo resultaram em muitos casos da doença, alguns fatais (GLOBAL POLIO ERADICATION INITIATIVE, 2010; TIMELINES..., 2016).

Em 1947, o pesquisador americano Jonas Salk (1914-1995) iniciou seus trabalhos em um novo laboratório médico, criado pela Fundação Científica Sarah Mellon. No ano seguinte, esse laboratório recebeu bolsa para o projeto de tipagem do poliovírus, e Salk resolveu usar um método recentemente desenvolvido à época de cultivo do vírus em tecido. Enquanto isso, Albert Sabin (1906-1993) continuava seus trabalhos com o processo mais difícil, usando macacos infectados com o poliovírus.

Anteriormente a Jonas Salk, Hilary Koprowski (1916-2013), havia iniciado estudos na busca de uma vacina oral contra a poliomielite. Em 1948, ele testou nele mesmo e em seu assistente sua vacina atenuada do poliovírus tipo II, inicialmente testada em chimpanzés. Ele e seu assistente "beberam" uma mistura do produto e não apresentaram nenhum efeito da doença, sendo esta considerada a primeira vacina poliomielite. Embora essa vacina tenha sido administrada em várias populações, nunca foi aprovada para uso mundial.

Em 1949, Jonas Salk desenvolveu uma vacina a partir de vírus inativado (morto), que, em 1954, foi testada em 45 mil crianças nos Estados Unidos. Ainda em 1949, David Bodian, MD, PhD (1910-1992), e Isabel Morgan, PhD (1911-1996), pesquisadores da Escola de Medicina Johns Hopkins, publicaram a identificação de três tipos de poliovírus, uma descoberta que seria crucial para o desenvolvimento de uma vacina que produz imunidade a todos os tipos do vírus. Pesquisas posteriores, grande parte desenvolvida por Jonas Salk, confirmaram a existência de apenas esses três tipos de vírus diferentes imunologicamente.

Em 1950, Koprowski realizou teste em crianças com a vacina tipo II em um estabelecimento de saúde. Esse teste, com a vacina desenvolvida em parceria com o pesquisador Herald R. Cox (1907-1986), demonstrou que nenhuma das 20 crianças vacinadas adoeceu, e todas elas desenvolveram anticorpos para o poliovírus tipo II.
Você sabia?

Em virtude do aumento do número de casos da doença, em 1938, o animador americano Eddie Canter pediu aos ouvintes da rádio para enviarem moedas à Casa Branca a fim de serem usadas pela Fundação Nacional para a Paralisia Infantil na luta contra a pólio; essa mobilização foi denominada Marcha do Dime (moeda de 10 centavos de dólar americano). 
Na época, os métodos de Hilary Koprowski geraram controvérsia considerável entre os que trabalhavam em vacinas experimentais, pois julgaram ser prematuro o teste de uma vacina viva em indivíduos humanos, e alguns se opuseram à aplicação de vacina em crianças institucionalizadas, embora a prática fosse frequente.

Dois anos após (1952), Salk e equipe, com o apoio da Fundação Nacional para Paralisia Infantil, iniciaram seus primeiros testes, em crianças portadoras de necessidades especiais institucionalizadas, com a vacina de vírus mortos da pólio contendo os três tipos de cepas; demonstraram, então, que todos os vacinados produziram anticorpos aos tipos de vírus na vacina. No ano seguinte, Salk aplicou a vacina em sua esposa e seus três filhos.

Em 1954, Albert Sabin desenvolveu a vacina atenuada da pólio, a primeira a ser aplicada por via oral. Por mimetizar

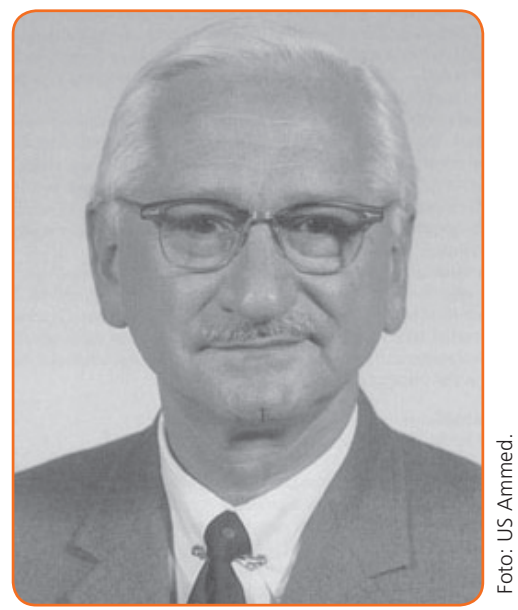

Albert Bruce Sabin (1906-1993), médico que desenvolveu a vacina poliomielite oral.

Fonte: Wikimedia Commons. o mecanismo de infecção do vírus selvagem, com a excreção do microrganismo atenuado no ambiente, a vacina Sabin facilita a obtenção de altos níveis de imunidade coletiva.

Em 1957, Koprowski iniciou uma série de testes de vacina atenuada do poliovírus, na atual República Democrática do Congo. A vacina utilizada continha apenas o vírus tipo I, pois este era responsável pela maioria dos casos de pólio. Vacinaram centenas de milhares de pessoas e ampliaram a vacinação para alguns locais na Europa. Com a entrada do Congo em um período de inquietação política e social, ficou difícil acompanhar os indivíduos vacinados e avaliar os resultados dos testes, embora pelo menos um estudo tenha confirmado a eficácia da vacina.

Em 1958 e 1959, testes de campo provaram que a vacina oral Sabin, de vírus vivo atenuado, era efetiva, e, em 1962, a vacina Salk foi substituída pela Sabin, superior em termos de administração fácil e que promove imunização de maior duração.

A partir de 2015, o PNI recomenda a vacina Salk até os 4 meses de vida, e a Sabin, a partir dos 6 meses até os 4 anos de idade.
Com a recomendação do Cirurgião Geral dos Estados Unidos, em 24 de agosto de 1960, a vacina viva oral de Sabin, do poliovírus tipo I, foi licenciada, seguida, com brevidade, pelo licenciamento de vacinas para 
os tipos II e III. Em 1963, foi oferecida a vacina com a combinação dos três tipos (GLOBAL POLIO ERADICATION INITIATIVE, 2010).

Em 14 de junho de 1980, o Brasil realizou a primeira campanha de vacinação em massa para a pólio, utilizando a vacina Sabin. Essa ação foi seguida de duas campanhas anuais até que, em 1989, foi registrado o último caso da doença no país.

\section{Vacina encefalite japonesa}

Em 1944, nos Estados Unidos da América, Maurice Hileman (19192005), trabalhando no laboratório E. R. Squibb and Son, auxiliou no desenvolvimento de uma vacina para a encefalite japonesa, destinada à proteção das tropas americanas na Segunda Guerra Mundial, nunca sendo testada em civis (TIMELINES..., 2016).

A encefalite japonesa (EJ) é a causa mais importante de encefalite viral na Ásia. O primeiro caso foi documentado em 1871, no Japão. A doença é provocada por um vírus semelhante aos vírus da febre amarela e da dengue. É transmitida ao homem pela picada de um mosquito, que põe seus ovos nas zonas alagadas dos campos de cultivo de arroz, nas zonas pantanosas e em pequenas coleções de águas paradas.

Estudos estimam que haja, aproximadamente, 68 mil casos clínicos de EJ no mundo a cada ano, com até 20.400 mortes devidas a essa doença (BULLETIN, WHO, outubro de 2011 ). Por não haver cura, a prevenção é fundamental e consiste na administração da vacina e em se evitar a picada do mosquito. A vacina é recomendada para viajantes com estadias prolongadas em área endêmica (JAPANESE..., 2015).

A vacina encefalite japonesa, embora não faça parte do calendário de rotina do PNI, existe no Brasil para administração de forma seletiva em militares ou civis que sejam enviados para trabalhos em áreas de risco. Existem três vacinas disponíveis, que não são comercializadas, mas utilizadas nessas situações especiais: duas vacinas inativadas e uma vacina de vírus vivo atenuado (TIMELINES..., 2016).

\section{Desafios atuais}

Vencemos muitos desafios na proteção à saúde, como a erradicação da pólio no país, mas outros tantos persistem. Tarefa árdua seria nomeá-los agora. Para nosso estudo, porém, merecem destaque especial o combate a determinadas doenças, com altas taxas de mortalidade e letalidade, e a produção de novas vacinas, como as da dengue, que abordaremos a seguir, e da Aids.

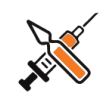

A vacina pólio continua no calendário de vacinação, pois, enquanto existirem países reservatórios da pólio no mundo, existirá o risco de termos a reemergência da doença (UNICEF BRASIL, 2013). 


\section{Vacina dengue}

Você sabia?

A dengue foi considerada virose benigna, sem letalidade, até 1953, quando houve um surto de dengue hemorrágico nas Filipinas.
A dengue é uma doença febril aguda, de grande relevância para o quadro de saúde pública não só no Brasil, mas em todos os países tropicais. É causada por vírus e tem como vetor os mosquitos de origem africana Aedes aegypti e Aedes albopictus.

O Aedes aegypti surgiu no Brasil ainda nos tempos da Colônia, trazido nos depósitos de água dos navios negreiros. Já o A. albopictus foi introduzido na década de 1980, e, apesar de não haver nenhum registro de exemplares adultos infectados com o vírus dengue no país, a espécie é alvo de estudos que monitoram o crescimento de sua população e investigam seus aspectos biológicos e ecológicos em comparação com os do A. aegypti.

O vírus da dengue se apresenta em quatro formas (sorotipos) distintas: DEN 1, DEN 2, DEN 3, DEN 4. Cada sorotipo desses desencadeia uma resposta imunológica diferente no organismo humano. A infecção por um dos quatro sorotipos de vírus da dengue tem demonstrado conferir proteção contra a reinfecção pelo mesmo sorotipo (homotípica), porém apenas proteção transiente contra uma infecção por sorotipo diferente (heterotípica secundária). Além disso, a infecção heterotípica secundária está associada a risco aumentado de doença grave.

O fato de existirem quatro sorotipos diferentes acarreta complexidade maior para o desenvolvimento de uma vacina contra a dengue. Ainda não há uma vacina disponível para a dengue, mas há alguns passos dados nessa direção (por meio de avaliação em estudos clínicos).

Atualmente, a candidata em estágio de desenvolvimento clínico mais avançado é uma vacina viva, atenuada e tetravalente (ou seja, contra os quatro sorotipos) que progride para estudos de eficácia Fase II. Nessa fase, a vacina é administrada em voluntários não imunes (Fase IIa) e imunes (Fase IIb) para avaliação da eficiência, eficácia, segurança, tolerância e aceitação do produto. Os resultados do estudo de eficácia Fase IIb, realizado na Tailândia, foram publicados em setembro de 2012, demonstrando que a vacina em teste foi capaz de reduzir em 56\% o número de casos da doença.

Apesar do desafio que se impõe no desenvolvimento e implantação desta e de outras vacinas, avanços significativos têm sido alcançados na pesquisa e produção de novos imunobiológicos. 


\section{Considerações finais}

Neste capítulo, observamos o esforço de diversos cientistas na descoberta de vacinas para controle de inúmeras doenças transmissíveis, as quais surgiram no mundo em proporções e consequências severas e assumiram grande importância na área da saúde pública.

Vimos e continuamos a ver a união de esforços de epidemiologistas, virologistas, geneticistas, entre outros, de diversas nacionalidades, para a descoberta de vacinas cada vez mais específicas, eficazes e aprimoradas. Continuaremos a enfrentar desafios, isso com respeito a dengue, malária e Aids, mas sabemos que, para elas, já existem pesquisas avançadas na busca de seus imunobiológicos adequados.

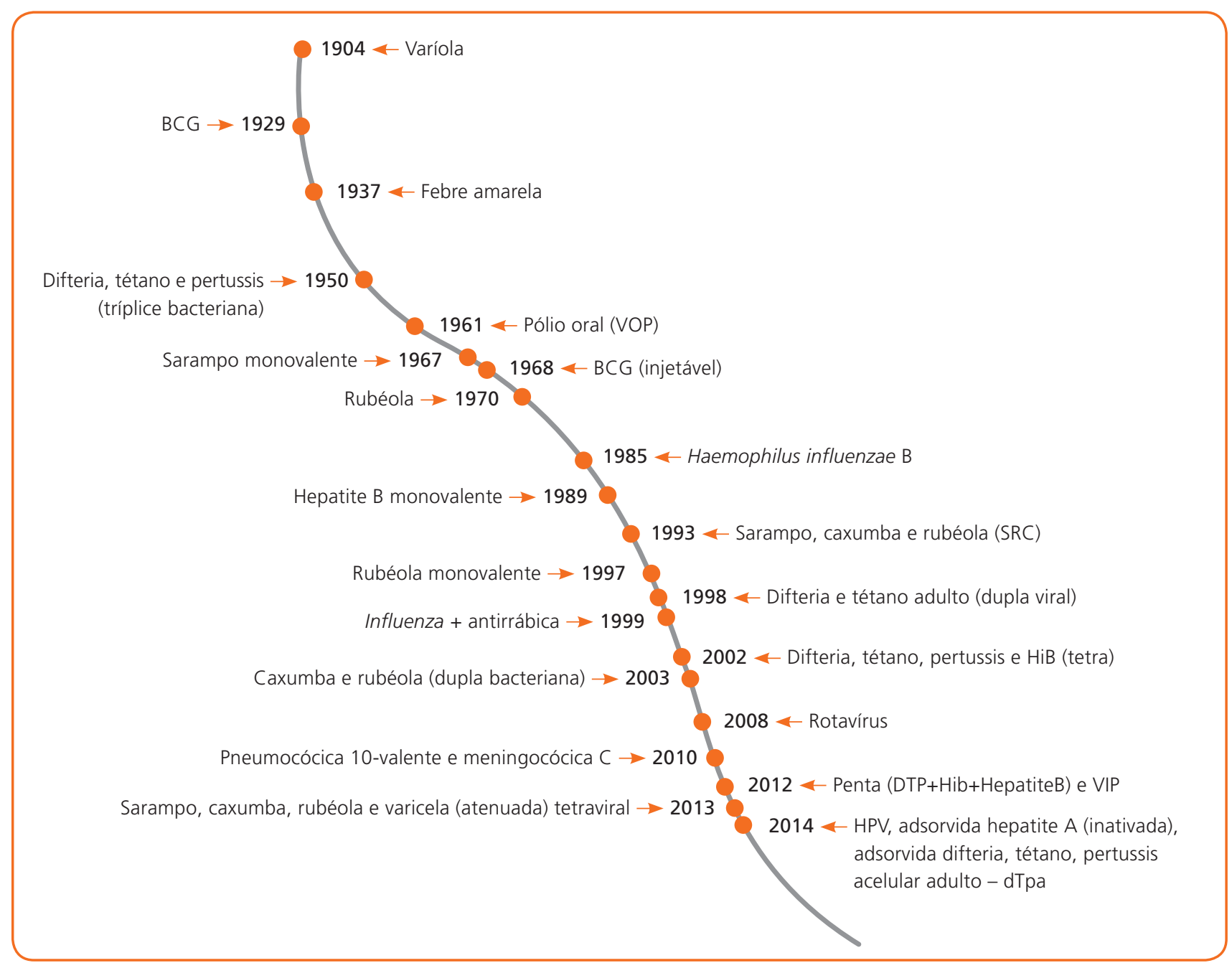




\section{Referências}

BENCHIMOL, J. L. Febre amarela: a doença e a vacina, uma história inacabada. Rio de Janeiro: Ed. Fiocruz, 2001.

BITTENCOURT, J. M. Taques. Penicilinoterapia em neurologia. Arquivos de Neuro-Psiquiatria, São Paulo, v. 3, n. 1, p. 78-95, jan./mar. 1945.

BOLETIM EPIDEMIOLÓGICO. Brasília, DF: Secretaria de Vigilância em Saúde/Ministério da Saúde, v. 46,2015

BRASIL. Ministério da Saúde. Programa Nacional de Imunizações (PNI): 40 anos. Brasília, DF, 2013.

BRASIL. Ministério da Saúde. Departamento Nacional de Endemias Rurais. História da febre amarela no Brasil. Rio de Janeiro, 1989.

BRASIL. Ministério da Saúde. Secretaria de Vigilância em Saúde. Guia de vigilância epidemiológica. 7. ed. Brasília, DF, 2009.

BRASIL. Ministério da Saúde. Secretaria de Vigilância em Saúde. Departamento de Vigilância Epidemiológica. Informe técnico da vacina pneumocócica 10-valente (Conjugada). Brasília, DF, 2010. Disponível em: <http://www.sgc.goias.gov.br/upload/links/arq_723_infotec.pdf>. Acesso em: 28 mar. 2014.

DOENÇA pneumocócica: sintomas, transmissão e prevenção. Rio de Janeiro: Instituto de Tecnologia em Imunoniológicos Bio-Manguinhos, 2014. Disponível em: <https://www.bio.fiocruz.br/index.php/ doenca-pneumococica-sintomas-transmissao-e-prevencao>. Acesso em: 30 jul. 2016.

DORES, G. B. HPV livro: 1. Epidemiologia do HPV. São Paulo: HPV Info Brasil, [2005?]. Disponível em: <http://hpvinfo.com.br/hpv-livro-1-epidemiologia-do-hpv/>. Acesso em: 30 jul. 2016.

FARHAT, C. K. et al. Imunizações: fundamentos e prática. 5. ed. São Paulo: Atheneu, 2008.

A FEBRE amarela no Brasil: memória de um médico da Fundação Rockefeller. História, Ciências, Saúde-Manguinhos, Rio de Janeiro, v. 5, n. 3, p. 733-754, nov. 1998/fev. 1999.

FERREIRA, K. V. et al. Histórico da febre amarela no Brasil e a importância da vacinação antiamarílica. Arquivos Brasileiros de Ciências da Saúde, v. 36, n. 1, p. 40-47, jan./abr. 2011.

GLOBAL POLO ERADICATION INITIATIVE. History of polio. Geneva: World Health Organization, 2010. Disponível em: <http://www.polioeradication.org/Polioandprevention/Historyofpolio.aspx>. Acesso em: 30 jul. 2016.

GRABENSTEIN, J. D.; KLUGMAN, K. P. A century of pneumococcal vaccination research in humans. Clinical Microbiology and Infection, v. 18, p. 15-24, 2012 Oct. Suplemento 5. doi: 10.1111/j.14690691.2012.03943.x. Epub 2012 Aug 6.

JAPANESE encephalitis. Washington, DC: Centers for Disease Control and Prevention, 2015. Disponível em: <http://www.cdc.gov/japaneseencephalitis/>. Acesso em: 30 jul. 2016. 
MELDAU, D. C. Intussuscepção. [São Paulo]: InfoEscola, [2006?]. Disponível em: <http://www. infoescola.com/doencas/intussuscepcao/>. Acesso em: 30 jul. 2016.

NASCIMENTO, D. R. A história da poliomielite. Rio de Janeiro: Garamond, 2010.

NEWMAN, L. Maurice Hilleman. BMJ, v. 330, n. 7498, Apr. 2005. Disponível em: <http://www.ncbi. nlm.nih.gov/pmc/articles/PMC557162/>. Acesso em: 30 jul. 2016.

QUADROS, A. C. Vacinas: prevenção à doença protegendo a saúde. São Paulo: Rocca, 2008.

RAMANI, Revathi R. et al. Impact of PCV7 on invasive pneumococcal disease among children younger than 5 years: a population-based study. American Journal of Public Health, v. 94, n. 6 , p. 958-959, June 2004. DOI: 10.2105/AJPH.94.6.958.

ROTAVIRUS. In: CENTERS FOR DISEASE CONTROL AND PREVENTION. Pink book. Washington, DC, [201-]. Disponível em: <http://www.cdc.gov/vaccines/pubs/pinkbook/rota.html>. Acesso em: 30 jul. 2016.

SÃO PAULO. Secretaria de Estado da Saúde. Centro de Vigilância Epidemiológica. Divisão de Imunização. Informe técnico: vacina contra o papilomavírus humano (HPV). São Paulo, 2014.

SILVA, M. N.; FLAUZINO, R. F. (Org.). Rede de frio: gestão, especificidades e atividades. Rio de Janeiro: Ed. Fiocruz, 2016. No prelo.

TAUBENBERGER, J.; MORENS, D. M. 1918 Influenza: the mother of all pandemics. CDC Emerging Infectious Diseases, v. 12, n. 1, Jan. 2006.

TIMELINES. In: THE HISTORY of vacines. Philadelphia: College of Physicians, 2016. Disponível em: <http://www.historyofvaccines.org/content/timelines/all>. Acesso em: 30 jul. 2016.

TUBO capilar. In: INFOPÉDIA: dicionários Porto Editora. Porto: Porto Ed., 2016. Disponível em: <http://www.infopedia.pt/\$tubo-capilar>. Acesso em: 30 jul. 2016.

UNICEF BRASIL. Ministério da Saúde realiza, em setembro, a $2^{\text {a }}$ fase da Campanha Nacional de Vacinação Infantil. Brasília, DF, 2013. Disponível em: <http://www.unicef.org/brazil/pt/ media_15482.htm>. Acesso em: 30 jul. 2016.

WEISER, Jeffrey N.; ROBBINS, J. B. Robert Austrian, 1916-2007: a biographical memoirs. Washington, DC: National Academy of Sciences, 2013.Disponível em: <http://www.nasonline.org/ publications/biographical-memoirs/memoir-pdfs/austrian-robert.pdf>. Acesso em: 30 jul. 2016.

WORLD HEALTH ASSEMBLY, 52, 1999, Geneva. Smallpox eradication: destruction of variola virus stocks: report by the Secretariat. Geneva, 1999. Disponível em: <http://www.who.int/iris/handle/10 665/79264\#sthash.8CHsTJ1d.dpuf >. Acesso em: 30 jul. 2016. 